\title{
EDUCAÇÃO COMO POSSIBILIDADE DE EFETIVAÇÃO "SOCIAL": A PROPOSTA PEDAGÓGICA DO IEMA ENQUANTO UMA REALIDADE TRANSFORMADORA
}

\author{
Education as a possibility of "Social" effectivity: The \\ pedagogical proposal of the IEMA as a transformative reality
}

José Henrique Sousa Assai'

\section{Resumo}

A filosofia social ocupa um lugar de destaque no âmbito da teoria crítica: em primeiro lugar, ela possui a tarefa de pensar o "Social" explicitando as contradições em uma determinada realidade; em segundo lugar, ao encetar a reflexão sobre o "Social",- entendido pelas práticas, relações e instituições sociais enquanto condições constitutivas para o exercício da liberdade -, a pesquisa crítica, sob a perspectiva sociofilosófica, se endereça para a identificação, análise e solução dos problemas sociais. Nesse sentido, a educação passa a ser considerada enquanto uma mediação fundamental para o processo transformador da sociedade constituindo-se, portanto, enquanto esfera copartícipe desse mesmo "Social" na medida em que em uma determinada ação pedagógica pode ser compreendida tanto por uma prática social quanto pelo estabelecimento de relações sociais mediadas por instituições sociais.

Sob o fito de uma leitura crítica, própria dos pressupostos da filosofia social e da teoria crítica, pretendo explicitar, nesta pesquisa de caráter work in progress, que o do Instituto de Educação Ciência e Tecnologia do Maranhão (IEMA) possui, no espírito de sua ação

\footnotetext{
Doutor em Filosofia pela Pontifícia Universidade Católica do Rio Grande do Sul (PUCRS), com estágio doutoral sanduíche na Universität Flensburg (Alemanha). Professor Adjunto da Universidade Federal do Maranhão (UFMA). ORCID: http://orcid.org/o0oo-0002-5846-4997. E-mail: jhsassai@ufma.br
} 
social, a orientação à práxis transformadora na medida em que intenta em efetivar aos assistidos pelo referido programa as condições mínimas de existência social nas quais são entendidas preliminarmente como a busca pela efetivação dos bens e dos direitos sociais.

Palavras-chave: Crítica. Educação. IEMA. Justiça Social.

\begin{abstract}
Social philosophy takes on a very important threshold of the critical theory: first, it has the task of thinking the "Social" explaining its internal contradictions; secondly, the "Social" is understood by practices, relationships and social institutions as constitutive conditions for the exercise of freedom and endeavour, from the social-philosophical approach, for the analysis and solution of the social problems. In this regard, the education is considered as a social mediation to emancipation of society and at the same time is constitutive part of "Social".

With regards to assumptions of critical theory, I aim explain, in this research work in progress, that IEMA (Social and Education Program Government from Maranhão State) has a telos to social emancipation inasmuch as picks up accomplish the struggle by minimal conditions of social existence understood basically as social assets and social rights.
\end{abstract}

Keywords: Critique. Education. IEMA. Social Justice.

\title{
Teoria crítica e educação: contextualizando a pesquisa
}

Quando Tilo Wesche apresentou a sua concepção acerca da teoria crítica e mais precisamente da pesquisa crítica concebendo o "diagnóstico de uma realidade que não deveria existir: de um sofrimento que ofende [...]" 2, ele o fez no intuito de situar precisamente àquilo que justifica uma teoria crítica: o interesse emancipatório. Na verdade, Wesche amplia a sua leitura a partir do momento em que delineia três fundamentos para uma pesquisa crítica: diagnóstico, análise e correção ${ }^{3}$. Penso que esses três aspectos não apenas recepcionam as ideias centrais de uma

\footnotetext{
2 WESCHE, Tilo. Reflexion, Therapie, Darstellung: Formen der Kritik. In: Jaeggi, Rahel; Wesche, Tilo (org). Was ist Kritik? 3.ed. Frankfurt am Main: Suhrkamp, 2013. p. $193-220$.

3 Id.Ibid., p. 200.
} 
teoria crítica, mas precisamente se vinculam com o pensar/agir à práxis 4 . Nesse sentido, essas três atitudes (sociais) associadas a uma abordagem imanente ${ }^{5}$ plenificam uma pesquisa crítica (teoria crítica) orientada para as transformações em uma determinada sociedade. Esse movimento "emancipador" pressupõe, por sua vez, um "olhar atento" para os problemas sociais em um específico contexto. Com base no supracitado delineamento, procurarei explicitar brevemente, nesta pesquisa work in progress, que a esfera do "Social" pode ser pensada filosoficamente pela variante da educação. Na medida em que se assume a atitude em revisitar as premissas da pesquisa crítica ${ }^{6}$, pretendo apresentar o fundamento da esfera do "Social" vinculado à realidade do projeto pedagógico do IEMA7 no qual intenta em promover efetivas condições básicas educacionais para o povo maranhense; projeto esse que é vinculado ao programa social "Mais IDH"8 e que também se encontra ancorado em um dos postulados mais fundamentais para a teoria crítica ou pesquisa crítica: o interesse

4 FRASER, Nancy, JAEGGI, Rahel. Capitalism: A Conversation in Critical Theory. Cambridge: Polity Press, 2018. 240p.

JAEGGI, Rahel, CELIKATES, Robin. Sozialphilosophie: Eine Einführung. München: C.H.Beck, 2017. 128p.

NOBRE, Marcos (org.). Curso Livre de Teoria Crítica. Campinas: Papirus, 2008. 302p.

OLIVEIRA, Nythamar de. Tractatus Politico-Theologicus: Teoria Crítica, Libertação e Justiça. Porto Alegre: Editora Fi, 2016. 271p.

PINZANI, Alessandro. Justiça Social e Carências. In: PINZANI, Alessandro, TONETTO, Milene C. (orgs.). Teoria Crítica e Justiça Social. Florianopólis: Nefiponline, 2012. p.134-149.

STAHL, Titus. Immanente Kritik: Elemente einer Theorie sozialer Praktiken. Frankfurt am Main: Campus Verlag, 2013. 475p.

5 FERRARA, Alessandro. Rethinking Critical Theory Once Again: Immanent Critique and Immanent Normativity. In: LUDOVISI, Stefano (org.). Critical Theory and the Challenge of Praxis: beyond reification. Farnham: Ashgate Publishing, 2015. p. 145 - 157.

- DEMIROVIC, Alex. "Continuar, ou o que significa falar da atualidade da Teoria Crítica?", Remate de Males, Campinas: n. 30, 2010, p. $9-24$.

ACKERLY, Brooke. Political Theory and Feminist Social Criticism. Cambridge: Cambridge University Press, 2000. 234p. (Contemporary Political Theory).

7 MARANHÃO (Estado). IEMA: Modelos, Resultados e Expansão-2018. São Luís, 2018, 20p.

8 MARANHÃO (Estado). Secretaria de Estado do Planejamento e Orçamento. Instituto Maranhense de Estudos Socioeconômicos e Cartográficos. Plano de Ação Mais IDH. São Luís, 2015. 113p. 


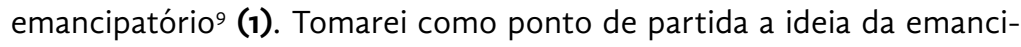
pação como elemento estruturante do pensamento crítico e inserida no plano programático da filosofia social. Em seguida, de forma lacônica e sob o prisma educacional pensado a partir da experiência maranhense, procurarei demonstrar que a esfera do "Social" ancorada por uma base de pensamento crítico envida a uma concepção ética de cunho solidário (2).

\section{Educação e filosofia social}

Um dos temas centrais da filosofia social é justamente o "Social" (Das Soziale); mas, o que ele é? E, para esta pesquisa, de que modo ele se articula com um pensamento crítico (programa socionormativo da teoria crítica) no qual possa se constituir enquanto uma mediação para se pensar a esfera educacional de modo emancipatória? Tratarei a seguir dessas duas questões ancorando-me nos pressupostos de Rahel Jaeggi.

A tentativa de definição sobre o que seja o "Social" é dada como parte de um projeto filosófico ancorado em uma determinada forma compreensiva de filosofia social onde se busca compreender a sociedade tanto de modo avaliativo quanto analítico ${ }^{10}$. O empreendimento desse projeto exige pari passu que a reflexão crítica deva ser combinada pela teoria social e pela ontologia social (cujo corolário enceta o pensar filosófico acerca das instituições sociais)". Com base nessa forma reflexiva, o "Social" busca responder à seguinte pergunta: "was wir tun sollen" (und warum)? Em outros termos,

\footnotetext{
9 FORST, Forst et.al. Sozialphilosophie und Kritik. 1.ed. Frankfurt am Main: Suhrkamp, 2009. 743p. JAEGGI, Rahel. Was ist Ideologiekritik? In: JAEGGI, Rahel; WESCHE, Tilo (orgs.). Was ist Kritik? 3.ed. Frankfurt am Main: Suhrkamp, 2013. p. $266-295$.

STAHL, 2013, p. $452-457$.

10 JAEGGI, CELIKATES, 2017, p.7.

$"$ HASLANGER, Sally. Resisting Reality: Social Construction and Social Critique. Oxford: University Press, 2012. 49op.

STEMMER, Peter. Normativität: Eine ontologische Untersuchung. Berlin: De Gruyter, 2008. 370p. IKÄHEIMO, Heikki, LAITINEN, Arto. Recognition and Social Ontology. Leiden: Brill, 2011. 398 p. HONNETH, Axel. Leiden an Unbestimmtheit: Eine Reaktualisierung der Hegelschen Rechtsphilosophie. Stuttgart: Reclam, 2001. 127p.
} 
"o que nós devemos fazer (e por que)?" Por se tratar exatamente de ter um caráter reflexivo, o "Social" passa também a ser entendido enquanto "práticas sociais, instituições e relações (sociais) enquanto condições constitutivas para a individualidade e a liberdade" 12; entretanto, cada elemento estruturante do "Social" é autocompreendido conjuntamente por aquilo que Jaeggi chamou de "instância de metarreflexão" (Instanz der Metareflexion) ${ }^{13}$.

Se eu entendi corretamente a ideia de Jaeggi acerca do "Social", o caráter metarreflexivo só é possível de ser tematizado enquanto expressão de um determinado pensamento filosófico se a reflexão for o paradigma para se pensar tanto a prática social quanto a instituição e a relação social. Nessa perspectiva, o social, com o "s" minúsculo, encontra-se inserido no "Social", com "s" maiúsculo", já que nesse último há a condição sócio-ontológica da reflexão filosófica na medida em que as três áreas supracitadas são orientadas, segundo Jaeggi, pelos seguintes questionamentos: Como se consegue a efetividade social? Como a sociedade está estruturada? O que são as instituições (sociais)? ${ }^{14}$. Essas perguntas denotam a relevância filosófica de, no mínimo, dois temas centrais nesta pesquisa: prática social e instituição social. Tratarei de ambos em seguida buscando explicitar seus respectivos potenciais vinculativos junto ao programa socioeducacional IEMA.

Em "Kritik von Lebensformen" "5, Jaeggi está convencida de que uma prática social só pode ser considerada enquanto prática (social) se a mesma for executada várias vezes e, de igual modo, seja habitual' ${ }^{16}$. Jaeggi considera que uma determinada ação não pode ser entendida como prática social se a mesma for realizada por uma pessoa de uma única vez. Nesse sentido, as práticas para serem "elevadas" ao patamar de "sociais" precisam ser executadas coletivamente e que, de certa forma, tais ações tenham as

\footnotetext{
12 JAEGGI, CELIKATES, 2017, p. 11.

13 JAEGGI, CELIKATES, 2017, p.11.

14 JAEGGI, CELIKATES, 2017, p.12.

15 JAEGGI, Rahel. Kritik von Lebensformen. 2.ed. Berlin: Suhrkamp Verlag, 2014. 451p.

16 Id.Ibid., p. 96.
} 
instituições como mediação para a execução de uma determinada ação'" Por outro lado, uma prática social é também entendida como um conjunto de ações regulativas. Nesse caso, as ações não possuem apenas regularidade (Regelmäbigkeit), mas, sobretudo, o caráter reflexivo (Regelhaftigkeit) na execução de uma dada ação. É exatamente nessa esfera reflexiva que se pode estabelecer uma diferenciação entre as tomadas de decisão. A diferença entre os termos no jogo linguístico em Jaeggi não é mera semântica para dar um "clichê" filosófico; muito pelo contrário, penso que o uso dos termos no idioma alemão confere um status diferenciador entre "o que é uma ação dotada de regularidade" e "o que é uma ação aferida por critérios reflexivos". Por isso mesmo Jaeggi utiliza o termo "praxisinterne Kriterien" 18 para caracterizar uma prática social "reflexiva" como instância mediadora dessa mesma prática na medida em que há um ensamblamento dos princípios de justificação para essa determinada ação.

Por fim, as práticas são sociais porque possuem regras constitutivas no intuito de efetivar sua(s) própria(s) prática(s), isto é, uma prática social não orienta apenas para um determinado procedimento social, mas, sobretudo, cria (princípio gerador), gera, faz nascer, de igual modo, novas formas de procedimento social fomentando, por assim dizer, novos papéis sociais. Sob o escopo da filosofia social, toda prática social é autocompreendida em seu próprio contexto - "práticas são 'práticas em conexão'”19 -; então, perante uma orientação crítico-reflexiva (teoria crítica) da filosofia social podemos estabelecer, na tentativa de instar tanto a análise quanto a crítica e a atitude corretiva, uma forma compreensiva de leitura imanente ${ }^{20}$ tomando como ponto de referência um hic et nunc. É nesse sentido que a presente pesquisa

\footnotetext{
17 Id.Ibid., p. 97.

18 Id.Ibid., p. 98.

19 JAEGGI, 2014, p. 104.

20 STAHL, 2013, p. $375-418$.

BITTNER, Rüdiger. Kritik, und wie es besser wäre. In: JAEGGI, Rahel; WESCHE,Tilo (orgs.). Was ist Kritik? 3.ed. Frankfurt am Main: Suhrkamp, 2013. p. 134-149.
} 
se vincula com o programa educacional do IEMA ao concebê-lo como uma efetiva possibilidade de transformação social no Maranhão.

O IEMA é, enquanto projeto educacional, oriundo de uma das ações do programa social "Mais IDH"21. Diante da perspectiva da filosofia social autocompreendida enquanto estrutura de pensamento e ação mediada por uma determinada forma compreensiva de teoria crítica, uma questão central é perquirir em que medida o IEMA pode ser entendido enquanto prática social. De outro modo, seria possível postular que a(s) prática(s) educacional (is) do IEMA são efetivamente práticas sociais? Vale ressaltar que

O Instituto Estadual de Educação, Ciência e Tecnologia do Maranhão (IEMA) foi criado no dia 02 de janeiro de $2015 \mathrm{com}$ o intuito de ampliar a oferta de educação profissional técnica de nível médio no estado. A proposta é implantar o Instituto em vários municípios maranhenses, oferecendo à sociedade infraestrutura, equipamentos e pessoal para o desenvolvimento de cursos técnicos integrados ao ensino médio, respeitando as necessidades locais e as prioridades estratégicas do Maranhão $0^{22}$.

Se por prática social incorre o processo de regularidade de ação, logo, sob o ponto de vista de um projeto processual e educacional para o Maranhão, podemos, sim, creditar ao IEMA a condição de uma determinada prática social. Ademais, conforme atesta o postulado básico do IEMA supracitado, as questões da necessidade local bem como da prioridade ${ }^{23}$ são modos de entender e efetivar o referido projeto educacional atendendo às demandas contextuais dos municípios assistidos pelo IEMA. Nesse caso, o IEMA é sub-

\footnotetext{
21 MARANHÃO, 2015, 113p.
}

ASSAI, José Henrique, OLIVEIRA, Nythamar de. Catirina entre desencanto e emancipação: Uma leitura filosófico-social do "Mais IDH", Veritas, Porto Alegre, v. 63, n. 2, p. 673-690, 2018.

22 MARANHÃO (Estado). IEMA. Disponível em:<http://www.iema.ma.gov.br/institucional/o-iema/>. Acesso em: 27 maio 2019.

23 SCANLON, T. M. Preference and Urgency, The Journal of Philosophy, v.72, n. 19, Princeton, p. $655-669,1975$. 
divido em duas grandes unidades: plena e vocacional ${ }^{24}$. Sob a primeira, há o endereçamento para o "Ensino Médio Técnico - Educação profissional e tecnológica em tempo integral"; já a segunda, trata da "educação profissional continuada". Em ambos os casos, na medida em que a pobreza ainda grassa no Maranhão, o fito fundamental da estratégia do executivo maranhense foi atender aos municípios assistidos pelo IEMA em suas reais necessidades objetivas no tocante aos seus contextos locais. Por outro lado, as condições caricaturais da pauperização, outrora caótica e sem perspectiva de mudança, começa a ter outro patamar: uma transformação efetiva não só na educação formal dos maranhenses, mas, sobretudo, na formação da cidadania. Os indicadores atestam uma real melhoria no cenário educacional do Maranhão25; porém, esses mesmos índices possuem uma autorreferencialidade na medida em que os gestores bem como os docentes e principalmente as comunidades, juntamente com os discentes, reconhecem o aperfeiçoamento do processo de ensino-aprendizagem em seus respectivos contextos.

Conforme atesta Jaeggi, no limiar entre a "regularidade" e a "reflexividade", o IEMA pode ser entendido enquanto uma prática socioeducativa com uma base precisamente "reflexiva", pois no mote do projeto-IEMA "uma escola pública de excelência é possível”26 estabeleceu-se uma tomada de decisão radical: priorizar a educação enquanto expressão da cidadania. É nesse sentido que as condições mínimas de existência social são efetivadas ${ }^{27}$ no sentido de entendê-las, por exemplo, como o acesso à educação formal de (com) qualidade.

No caso da ideia de instituição social, na qual Jaeggi retoma o pressuposto honnethiano da "autorrealização individual", há um preclaro objetivo

\footnotetext{
24 MARANHÃO, 2018, p. 5.

25 MARANHÃO (Estado). IEMA. Disponível em: <http://www.iema.ma.gov.br/conquistas-e-resultados/>. Acesso em: 27 maio 2019.

26 MARANHÃO, 2018, p. 19.

27 PINZANI, 2012. p. $134-159$.

PINZANI, Alessandro. De objetos da política a sujeitos da política: dar voz aos pobres, Ética, Florianópolis, n. 3, p. $83-101,2011$.
} 
associado a ela: a promoção aos bens e direitos sociais ${ }^{28}$. A educação é, enquanto processo social e formal de uma determinada comunidade histórica, entendida como um desses ben $\mathrm{s}^{29} \mathrm{e}$, nesse sentido, tanto o sujeito particular quanto o sujeito coletivo conseguem efetivar as suas práticas sociais na medida em que são assistidos pelos bens sociais e direitos sociais. Para a presente pesquisa deve-se levar a sério o pressuposto ético da solidariedade como forma de assentar uma possível base mínima de fundamentação para uma determinada práxis social cunhada no modelo educacional do IEMA. É exatamente nesse sentido que o agir solidário se constitui como uma referência ética no tocante ao projeto educacional do IEMA, pois se entende nessa pesquisa por solidariedade uma determinada forma de ação cooperativa ${ }^{30}$.

\section{Prática educacional enquanto ética solidária}

Tomando por consideração a sessão anterior quando esbocei um vínculo entre a ideia de forma de vida e a prática social (educacional) do IEMA uma questão permanece sob o escrutínio de uma pesquisa crítica: a relação entre "o que nós queremos e o que nós já fazemos ou podemos fazer" ${ }^{\prime \prime}$. Se uma determinada forma de vida pode ser compreendida, sob o escopo de uma filosofia social ${ }^{32}$, enquanto uma maneira de agir endereçada à resolução de problemas (Problemlösungshandeln) ${ }^{33}$, então o programa pedagógico do IEMA, na medida em que é entendido como uma forma de vida (socioeducacional), passa a responder à supracitada perquirição tentando, por assim dizer, executar o êxodo do "o que queremos" para o

\footnotetext{
28 JAEGGI, Rahel. Was ist eine (gute) Institution? In: FORST, Rainer et.al. Sozialphilosophie und Kritik. 1.ed. Frankfurt am Main: Suhrkamp, 2009. p. 528 - 544.

29 SOBRINHO, José Dias. Educação superior: bem público, equidade e democratização, Avaliação, Campinas, n.1, v.8, p. $107-126,2013$.

30 JAEGGI, Rahel. Solidarity and Indifference. In: MEULEN, Ter, ARTS, Will, MUFFELS, R. (org.). Solidarity in Health and Social Care in Europa. Dordrecht: Springer, 2001. 495p.

31 JAEGGI, 2014, p. 447.

32 DETEL, Von Wolfgang. Philosophie des Sozialen. Stuttgart: Reclam, 2007. 191p.

33 JAEGGI, 2014, p. 448.
} 
"que podemos fazer". É nesse sentido que as pretensões reivindicatórias expressas no postulado do "respeito às necessidades locais e às prioridades estratégicas do Maranhão" ganham força e assumem um lugar de destaque nas políticas públicas na sociedade maranhense. Tais necessidades e prioridades ${ }^{34}$ podem ser pensadas tomando por base um critério ético da solidariedade. A seguir, encaminho minhas considerações finais buscando estabelecer a ideia básica acerca da ação solidária vinculada com a prática socioinstitucional do IEMA. Para tal intento, procurarei tratar sobre o tema da solidariedade - muito discutido no interior da filosofia social, filosofia política, ética, moral etc. -, no qual se assenta em uma pluralidade nocional, a partir das considerações de Rahel Jaeggi.

Sob o esteio de uma filosofia social ocupada pelo pensamento e pela ação à práxis transformadora de um determinado contexto social no qual esteja eivado de contradições obliterantes para a efetivação dos bens e direitos sociais, Jaeggi concebe a ideia de solidariedade como uma maneira de agir socialmente na qual possua um telos à efetivação ao bem-estar ${ }^{35}$. Não se deve olvidar, entretanto, a difícil tarefa em definir o que seja uma concepção de bem-estar principalmente quando ela se situa enredada pela variedade de saber(es) no interior da(s) filosofia(s). Por outro lado, perante uma situação patológica socia ${ }^{36}$, entende-se por bem-estar a efetiva luta pelas condições de se ter garantidos os bens e os direitos sociais ${ }^{37}$. É nesse sentido que a luta pela efetivação dos bens sociais pode ser entendida

\footnotetext{
34 SCANLON, 1975, p. $655-669$.
}

35 JAEGGI, 2001, p. 287.

SANDEL, Michael J. Justiça: o que é fazer a coisa certa. Tradução Heloísa Matias e Maria Máximo. 24.ed. Rio de Janeiro: Civilização Brasileira, 2017. 349p.

PIKETTY, Thomas. Um Estado social para o século XXI. In: PIKETTY, Thomas. O capital no século XXI. Tradução de Mônica de Bolle. Rio de Janeiro: Intrínseca, 2014. cap. 13.

36 HONNETH, Axel. Pathologien der Vernunft: Geschichte und Gegenwart der Kritischen Theorie. Frankfurt am Main: Suhrkamp Verlag, 2007. 239p.

JAEGGI, Rahel. Fortschritt und Regression. Frankfurt am Main: Suhrkamp Verlag, 2019. 20op.

37 BRUNKHORST, Hauke. Solidarität: Von der Bürgerfreundschaft zur globalen Rechstgenossenschaft. 1.ed. Frankfurt am Main: Suhrkamp Verlag, 2002. 246p. 
enquanto um "Platzhalter" na democracia ${ }^{38}$, ou seja, a busca por (uma) efetiva(s) política(s) pública(s) de cunho educacional - como é o caso do IEMA - visa (m) prover não apenas uma ideia abstrata de bem-estar, mas, sobretudo, vinculá-la ao enfrentamento de cenários de injustiça social ${ }^{39}$. O que pesa o fato da precarização sistêmica da educação ao longo de tantos anos no Maranhão é a possibilidade de pensar que o programa socioeducacional do IEMA garante minimamente melhores condições formais do ensino e da pesquisa. Isso ocorre não apenas pelos prêmios a nível nacional e internacional conquistados pelo IEMA, porém, e mais precisamente, pelo projeto de formação e de estruturação do pensar e do agir sociopolítico. $O$ índice de evasão escolar diminuiu drasticamente ( $2 \%$ em 2018) ao passo que a frequência escolar ficou na média de $98 \%$ (dados de 2018) ${ }^{40}$. Importante ter presente que os índices de evasão escolar assim como de frequência eram muito ruins no Maranhão até a implantação do IEMA. Os referidos dados atestam uma forma de ação compreensivamente articulada pelo que eu caracterizo, de acordo com Jaeggi, de agir solidário de modo cooperativo não-instrumental.

Sob o ponto de vista de Jaeggi, sobre o pressuposto básico para se entender a solidariedade é preciso observar que: primeiramente, uma ação cooperativa de cunho instrumental; em segundo lugar, uma ação cooperativa não-instrumental. A cooperação instrumental é entendida "como puro meio para se alcançar um fim individual|"41 e, nesse aspecto, a cooperação não se efetiva enquanto um valor em si mesmo permitindo-se pensar de que tal modo cooperativo não se estabeleceria como uma forma de vida ética.

\footnotetext{
38 HELD, David. Models of Democracy. 3.ed. Cambridge: Polity Press, 2006. 349p.

39 BUFACCHI, Vittorio. Social Injustice: Essays in Political Philosophy. 1.ed. New York: Palgrave Macmillan, 2012. 202p.

40 IEMA, 2018, p. 11.

${ }^{41}$ JAEGGI, 2001, p.293.
} 
No tocante ao segundo modelo (não-instrumental), a solidariedade passa a ser caracterizada como um "objetivo comum" de todos os participantes de uma determinada ação social, de modo que

[...] os objetivos a serem alcançados são objetivos comuns. Os interesses são interesses comuns; ou seja, não consigo mesmo descrever meus interesses e objetivos além dos objetivos dos outros. Estes são intrinsecamente "objetivos comuns" porque eles são constituídos apenas em comum. A cooperação é "não-instrumental" na medida em que uma vez que não se usa apenas os outros para alcançar um objetivo individual. O interesse do indivíduo deve ser entendido como “interesse no interesse dos outros". Uma greve pode servir de exemplo para ambos os modelos, instrumental bem como a cooperação não-instrumental ${ }^{42}$.

O caráter constitutivo da ação solidária sob a forma do objetivo comum parte do princípio de que todos os envolvidos agem "em comum" e em nome do "objetivo que é comum a todos os envolvidos". É pensando dessa forma que a proposta do IEMA atinge os municípios onde se faz presente. As demandas de cada região são ouvidas pelas Secretarias do Estado onde mediante o procedimento da "escuta" do povo mais pobre ${ }^{43}$ o poder executivo pode organizar os cursos para as respectivas unidades educacionais (plenas ou vocacionais) ${ }^{44}$. As unidades plenas estão em sete municípios em diferentes regiões ao longo do Maranhão: Axixá - Bacabeira - Coroatá - Pindaré-Mirim - São José de Ribamar - São Luís - Timon. De igual modo, as unidades vocacionais estão em todas as regiões do Estado do Maranhão: Açailândia; Barra do Corda; Bequimão; Carolina; Caxias;

\footnotetext{
42 JAEGGI, 2001, p.293.

43 PINZANI, 2011, p. $83-101$.

${ }_{44}$ IEMA, 2018, p. 5.
} 
Codó; Imperatriz; Pedreiras; Pinheiro; Ribeirãozinho; São Luís - Escola de Cinema / São Luís - Estaleiro Escola e São Luís - Praia Grande.

No intuito do estabelecimento das unidades plenas e vocacionais do IEMA leva-se em conta a "voz dos mais carentes" que passa a ser não apenas ouvida - conforme atestam os procedimentos citados a seguir - mas, sobretudo, torna-se uma condição de efetivar a justiça social 45 , pois possibilita a todos os alunos a capacidade de que eles possam ter um bem-estar no qual seja mediado pela melhoria na conjuntura educacional de sua própria região.

Retomando o tema das demandas, que serve de ponto de referência para uma ação ética de cunho solidário, há um processo de escolha para os cursos técnicos em cada município onde o IEMA possa vir a se estabelecer ${ }^{46}$ : pesquisas preliminares sobre APLs e potencialidades de cada município, rodadas de diálogos nos municípios, análise dos questionários, audiências públicas e aplicação de questionários, divulgação dos cursos. Uma tácita forma de "construtivismo" sociopolítico com fins educacionais é realizada na medida em que as pessoas das comunidades são ouvidas e atendidas em grande parte de suas reivindicações, especificamente, no que diz respeito à esfera educacional: quais cursos desejam e que estejam vinculados com as necessidades mais prementes de cada município e/ou região. Nesse caso, um projeto educacional do porte do IEMA para um povo quase que integralmente desprovido de políticas públicas é fundamental e, sob o ponto de vista desta pesquisa, se caracteriza enquanto uma forma ética compreensivamente não-instrumental na medida em que todos os participantes (munícipes e o Executivo maranhense) discutem conjuntamente a respeito de quais cursos técnicos são os mais importantes para a formação básica dos jovens de cada município/região. Cursos esses que auxiliam não apenas no processo de evitar a evasão escolar,

\footnotetext{
45 Uma interessante referência na qual revisita os argumentos basilares de Amartya Sen no que diz respeito ao tema do "capability approach". Cf. ROBEYNS, Ingrid. The Capability Approach (and Social Justice). In: GAUS, Gerald F., D'AGOSTINO, Fred (org.). The Routledge Companion to Social and Political Philosophy. New York: Routledge, 2013. p. $456-466$.

${ }_{46}$ IEMA, 2018, p. 9.
} 
mas também constroem plataformas práticas ${ }^{47}$ para o encaminhamento à vida profissional. Nesse último caso, o IEMA conta com a plataforma "Contrata A $\hat{e}^{\text {"48 }}$ que agrega todos os discentes egressos de todos os cursos permitindo, assim, que as empresas possam contratá-los.

Perante o crivo da teoria crítica e da filosofia social, ambas pensadas sob o esteio da transformação efetiva das condições reais de uma determinada sociedade, o desafio em se buscar soluções aos problemas sociais - e no caso da esfera educacional - não deve ser tratado sob o plano meramente formal; porém e, mais especificamente, "as soluções devem ser essenciais" ${ }^{\prime \prime 9}$. A essencialidade reside justamente no espírito de um programa socionormativo da teoria crítica cujo repto é a constante solução das patologias sociais. De fato, em uma sociedade onde a educação não tinha o devido olhar acurado e a atenção para efetivas políticas públicas pode-se predicar que a mesma padece patologicamente em sua constituição social. A realidade do IEMA demonstra que, como prevê em sua plataforma, "uma educação pública de excelência é possível!".

\section{Referências}

ACKERLY, Brooke. Political Theory and Feminist Social Criticism. Cambridge: Cambridge University Press, 2000. (Contemporary Political Theory). https:// doi.org/10.1017/s000305540050001x

\footnotetext{
47 O IEMA criou por meio das Resoluções $n^{\circ} 86$ e 87 ( 25 de abril de 2018) os Círculos "Rosa Mochel" de Humanidades e o Círculo "Maria Firmina" de Linguagens. Fazem parte desses Círculos os docentes das áreas de História, Geografia, Filosofia e Sociologia das Unidades Plenas e de Linguagens os professores de Língua Portuguesa, Língua Inglesa, Espanhola, Artes e Educação Física. A tarefa fundamental dos Círculos é "integrar o trabalho dos professores da área de Humanidades em apoio prioritário ao desenvolvimento da educação profissional e tecnológica do IEMA tendo por base epistemológica de inspiração os círculos de cultura de Paulo Freire, buscando promover a cooperação, a integração e a articulação dos professores das áreas de linguagens, códigos e suas tecnologias, ciências humanas e suas tecnologias". Cf. IEMA. Redes. Disponível em: <http:/ /www.iema. ma.gov.br/rede/>. Acesso em 26 jun. 2019.

${ }_{48}$ MARANHÃO (Estado). lema: Plataforma Contrata Aê. Disponível em: <https://contrataae. iema.ma.gov.br/>. Acesso em 26 jun. 2019.

49 MÉSZÁROS, István. A educação para além do capital. Tradução Isa Tavares. 2.ed. São Paulo: Boitempo, 2008. 9op.
} 
ASSAI, José Henrique, OLIVEIRA, Nythamar de. Catirina entre desencanto e emancipação: Uma leitura filosófico-social do "Mais IDH", Veritas, Porto Alegre, v. 63, n. 2, p. 673-690, 2018. https://doi.org/10.15448/1984-6746.2018.2.31810 BRUNKHORST, Hauke. Solidarität: Von der Bürgerfreundschaft zur globalen Rechstgenossenschaft. 1.ed. Frankfurt am Main: Suhrkamp Verlag, 2002.

BUFACCHI, Vittorio. Social Injustice: Essays in Political Philosophy. 1.ed. New York: Palgrave Macmillan, 2012.

DEMIROVIC, Alex. Continuar, ou o que significa falar da atualidade da Teoria Crítica? Remate de Males, Campinas, n. 30, p. 9-24, 2010. https:/doi. org/10.20396/remate.v30i1.8636261

FERRARA, Alessandro. Rethinking Critical Theory Once Again: Immanent Critique and Immanent Normativity. In: LUDOVISI, Stefano (org.). Critical Theory and the Challenge of Praxis: beyond reification. Farnham: Ashgate Publishing, 2015. p. 145 - 157. https://doi.org/10.4324/9781315575117

FORST, Rainer et.al. Sozialphilosophie und Kritik. 1. ed. Frankfurt am Main: Suhrkamp, 2009.

FRASER, Nancy, JAEGGI, Rahel. Capitalism: A Conversation in Critical Theory. Cambridge: Polity Press, 2018. https://doi.org/10.1057/s41296-018-00304-W HASLANGER, Sally. Resisting Reality: Social Construction and Social Critique. Oxford: University Press, 2012. https://doi.org/10.1093/acprof:oso/9780199892631.003.0003

HELD, David. Models of Democracy. 3. ed. Cambridge: Polity Press, 2006. . HONNETH, Axel. Pathologien der Vernunft: Geschichte und Gegenwart der Kritischen Theorie. Frankfurt am Main: Suhrkamp Verlag, 2007. https:/doi. org/10.1007/978-3-531-90227-2

HONNETH, Axel. Leiden an Unbestimmtheit: Eine Reaktualisierung der Hegelschen Rechts-philosophie. Stuttgart: Reclam, 2001.

IEMA. Redes. Disponível em: http://www.iema. ma.gov.br/rede/. Acesso em 26 jun. 2019

IKÄHEIMO, Heikki; LAITINEN, Arto. Recognition and Social Ontology. Leiden: Brill, 2011. https://doi.org/10.1163/ej.9789004202900.i-398

JAEGGI, Rahel. Fortschritt und Regression. Frankfurt am Main: Suhrkamp Verlag, 2019. 
JAEGGI, Rahel, CELIKATES, Robin. Sozialphilosophie: Eine Einführung. München: C.H.Beck, 2017. https://doi.org/10.17104/9783406640575

JAEGGI, Rahel. Kritik von Lebensformen. 2. ed. Berlin: Suhrkamp Verlag, 2014. https://doi.org/10.1515/srsr-2015-0077

JAEGGI, Rahel. Was ist Ideologiekritik?. In: JAEGGI, Rahel; WESCHE,Tilo (org.). Was ist Kritik? 3.ed. Frankfurt am Main: Suhrkamp, 2013. p. 266 - 295.

JAEGGI, Rahel. Solidarity and Indifference. In: MEULEN, Ter; ARTS, Will; MUFFELS, R. (org.). Solidarity in Health and Social Care in Europa. Dordrecht: Springer, 2001. https://doi.org/10.1007/978-94-015-9743-2_1

MARANHÃO (Estado). lema: Plataforma Contrata Aê. Disponível em: https:// contrataae. iema.ma.gov.br/. Acesso em 26 jun. 2019.

MARANHÃO (Estado). Secretaria de Estado do Planejamento e Orçamento. Instituto Maranhense de Estudos Socioeconômicos e Cartográficos. Plano de Ação Mais IDH. São Luís, 2015.

MARANHÃO (Estado). IEMA: Modelos, Resultados e Expansão - 2018. São Luís, 2018.

MARANHÃO (Estado). IEMA. Disponível em: http://www.iema.ma.gov.br/ institucional/o-iema. Acesso em: 27 mai. 2019.

MÉSZÁROS, István. A educação para além do capital. Tradução Isa Tavares. 2. ed. São Paulo: Boitempo, 2008. https://doi.org/10.5380/nesef.v2i2.54651 NOBRE, Marcos (org.). Curso Livre de Teoria Crítica. Campinas: Papirus, 2008. OLIVEIRA, Nythamar de. Tractatus Politico-Theologicus: Teoria Crítica, Libertação e Jus-tiça. Porto Alegre: Editora Fi, 2016.

PIKETTY, Thomas. Um Estado social para o século XXI. In: PIKETTY, Thomas. O capital no século XXI. Tradução de Mônica de Bolle. Rio de Janeiro: Intrínseca, 2014. Cap.13. https://doi.org/10.5380/geografar.v12i2.56480

PINZANI, Alessandro. Justiça Social e Carências. In: PINZANI, Alessandro; TONETTO, Milene (org.). Critical Theory and Social Justice. Florianópolis: Nefiponline, 2012. p. $134-159$.

PINZANI, Alessandro. De objetos da política a sujeitos da política: dar voz aos pobres, Ética, Florianópolis, n. 3, p. 83-101, 2011. https://doi.org/10.5007/ 1677-2954.2011v10n3p83 
ROBEYNS, Ingrid. The Capability Approach (and social justice). In: GAUS, Gerald F.; D'AGOSTINO, Fred (org.). The Routledge Companion to Social and Political Philosophy. New York: Routledge, 2013. p. 456-466. https://doi. org/10.4324/9780203092231.ch40

SANDEL, Michael J. Justiça: o que é fazer a coisa certa. Tradução Heloísa Matias e Maria Máximo. 24. ed. Rio de Janeiro: Civilização Brasileira, 2017.

SCANLON, T. M. Preference and Urgency, The Journal of Philosophy, Princeton, v. 72, n. 19, p. $655-669,1975$.

SOBRINHO, José Dias. Educação superior: bem público, equidade e democratização, Avaliação, Campinas, n. 1, v. 8, p. 107 - 126, 2013. https://doi. org/10.1590/s1414-40772013000100007

STAHL, Titus. Immanente Kritik: Elemente einer Theorie sozialer Praktiken. Frankfurt am Main: Campus Verlag, 2013. https://doi.org/10.1515/srsr-2015-0064 STEMMER, Peter. Normativität: Eine ontologische Untersuchung. Berlin: De Gruyter, 2008.

WESCHE, Tilo. Reflexion, Therapie, Darstellung: Formen der Kritik. In: JAEGGI, Rahel; WESCHE, Tilo (org.). Was ist Kritik? 3. ed. Frankfurt am Main: Suhrkamp, 2013. p. 193-220. https://doi.org/10.1515/auk-2013-0110

\section{Endereço Postal}

\section{José Henrique Sousa Assai}

Universidade Federal do Maranhão

Coordenação de Ciências Humanas

Rua Urbano Santos S/N - Centro

CEP: $65900-410$

Imperatriz - MA 